\title{
Reactivity towards singlet oxygen of propofol inside liposomes and neuronal cells
}

\author{
B. Heyne ${ }^{\mathrm{a}}$, D. Brault ${ }^{\mathrm{b}}$, M.-P. Fontaine-Aupart ${ }^{\mathrm{c}}$, S. Kohnen ${ }^{\mathrm{d}}$, F. Tfibel ${ }^{\mathrm{c}}$, \\ A. Mouithys-Mickalad ${ }^{\text {d, G. Deby-Dupont }}{ }^{\mathrm{d}}$, P. Hans ${ }^{\mathrm{e}}$, M. Hoebeke,* \\ ${ }^{a}$ Department of Physics, Institute of Physics (B5), Biomedical Spectroscopy (C.O.R.D.), University of Liège, Allée du 6 Août, 17, 4000 Liège, Belgium \\ ${ }^{\mathrm{b}}$ Laboratoire de Biophysique Moléculaire Cellulaire and Tissulaire (BIOMOCETI), CNRS UMR 7033, Université Paris 6, \\ Site SERONO-RN7, 91030 EVRY, France \\ ${ }^{\mathrm{c}}$ Laboratoire de Photophysique Moleculaire, UPR CNRS 3361, Universite Paris-Sud, 91405 Orsay, France \\ ${ }^{\mathrm{d}}$ Department of Chemistry, Institute of Chemistry (B6), Center of Oxygen Research and Development (C.O.R.D.), University of Liège, 4000 Liège, Belgium \\ ${ }^{\mathrm{e}}$ Department of Anesthesia and Intensive Care Medicine, University Hospital of Liège, 4000 Liège, Belgium
}

Received 25 November 2004; received in revised form 30 March 2005; accepted 1 April 2005

Available online 20 April 2005

\begin{abstract}
Singlet oxygen $\left({ }^{1} \mathrm{O}_{2}\right)$, a reactive oxygen species, has been found to be implicated in many cellular events and pathological disorders. Herein, we investigated the reactivity of ${ }^{1} \mathrm{O}_{2}$ towards the anaesthetic agent propofol (PPF) encapsulated within DMPC liposomes. By time resolved luminescence, the rate constant of ${ }^{1} \mathrm{O}_{2}$ quenching by PPF was evaluated, depending on the location of the sensitizer, with following values: $1.35 \pm 0.05 \times 10^{7} \mathrm{M}^{-1} \mathrm{~s}^{-1}$ for deuteroporphyrin (as embedded source) and $0.8 \pm 0.04 \times 10^{7} \mathrm{M}^{-1} \mathrm{~s}^{-1}$ for uroporphyrin (as external source), respectively. The nature of the oxidation product, resulting from the reaction of ${ }^{1} \mathrm{O}_{2}$ with PPF, was determined using absorption and HPLC techniques. Finally, the in vitro protective effect of PPF towards the ${ }^{1} \mathrm{O}_{2}$-induced neuronal cell toxicity was evaluated in terms of cell viability.
\end{abstract}

(C) 2005 Elsevier B.V. All rights reserved.

Keywords: Propofol; Singlet oxygen; Antioxidant; Phenoxyl radical; Liposome; Neuro-2a

\section{Introduction}

It is well established that cellular damage occurs when the intracellular production of reactive oxygen species exceeds the capacity of the antioxidant defences to remove the offending oxidants [1]. Among oxidant species, singlet oxygen $\left({ }^{1} \mathrm{O}_{2}\right)$ is one of the most important nonradical byproducts of the oxygen metabolism. In pathological conditions, ${ }^{1} \mathrm{O}_{2}$ is formed either during the inflammatory processes or by photosensitization in light-exposed areas. In fact, ${ }^{1} \mathrm{O}_{2}$ has been shown to be generated by activated polymorphonuclear neutrophils (PMN) [2,3]. The prooxidative enzyme NADPH-oxidase generates superoxide

\footnotetext{
* Corresponding author. Tel.: +32436636 51; fax: +3243662813.

E-mail address: M.Hoebeke@ulg.ac.be (M. Hoebeke).
}

anions that dismute into hydrogen peroxide. This latter species can react with hypochlorite acid $(\mathrm{HOCl})$ produced by myeloperoxidase activity to form ${ }^{1} \mathrm{O}_{2}[2-4]$. In addition, ${ }^{1} \mathrm{O}_{2}$ may also be produced in photodynamic reactions with endogenous (porphyrins, flavins,...) or exogenous (tetracycline, ...) sensitizers $[5,6]$.

For several years, growing interest has been given to the role of ${ }^{1} \mathrm{O}_{2}$ in pathological situations and particularly in the oxidative stress induced by postischemic reperfusion. Even if no direct evidence of its formation in vivo has been described to date, a number of indirect indices shows its involvement in ischemia-reperfusion injury $[7,8]$.

Due to its high reactivity, ${ }^{1} \mathrm{O}_{2}$ is capable of reacting with a large variety of biological molecules such as lipids, DNA and proteins. Indeed, ${ }^{1} \mathrm{O}_{2}$ has been reported to react directly with carbon-carbon double bonds by an ene reaction to give peroxides [5,9]. Thus, the direct addition of this 
reactive oxygen species to lipid membranes can rapidly cause peroxidation [5,9]. In addition, it has also been worked out that ${ }^{1} \mathrm{O}_{2}$ is capable of reacting preferentially with the guanine moiety in DNA yielding to 8-oxoDG [10]. Furthermore, several amino acids such as histidine and tryptophan have been found to be particularly sensitive to ${ }^{1} \mathrm{O}_{2}$ attack, resulting in protein alteration and/or inactivation of enzymes [11].

2,6-diisopropylphenol, a widely used anaesthetic agent known as propofol (PPF), has been reported to attenuate experimental reperfusion injury in cerebral cortex $[12,13]$. Its neuroprotective activity is attributed to its ability to act as an antioxidant. In recent studies, attention has been focussed on its importance as a free radical scavenger. PPF has been reported to inhibit lipid peroxidation reactions [14-16] and to react with hydroxyl radicals [17] as well as with peroxynitrite $[17,18]$. The antioxidant effect of PPF has been attributed to its chemical similarity with other well-known phenolic antioxidants such as butylhydroxytoluene (BHT) and $\alpha$-tocopherol. On the other hand, several papers have been published describing the behaviour of phenols as potent ${ }^{1} \mathrm{O}_{2}$ scavengers [19-21]. Thus, ${ }^{1} \mathrm{O}_{2}$ inhibition by PPF could be an additional mode of biological action of the anaesthetic agent. We previously demonstrated in a study in aqueous medium that PPF really behaved as a scavenger of ${ }^{1} \mathrm{O}_{2}$ [22]. It is well established that the main biological molecules affected by ${ }^{1} \mathrm{O}_{2}$ are located in the cell membrane $[9,11]$ and according to Murphy et al. [23], PPF accumulates in biomembranes quite rapidly. Thus, in order to gain insight into the reactivity of PPF towards ${ }^{1} \mathrm{O}_{2}$ in membranes, this reaction was studied using liposomes. These simple vesicles containing an aqueous phase enclosed by a phospholipid membrane are considered as a membrane model [24]. In order to avoid any possible reaction between ${ }^{1} \mathrm{O}_{2}$ and the lipid moiety, we used unilamellar liposomes made of dimyristoylphosphatidylcholine, i.e. with completely saturated lipidic chains.

The present study was also designed to assess the neuroprotective activity of PPF to prevent the ${ }^{1} \mathrm{O}_{2}$-induced cell death.

\section{Materials and methods}

\subsection{Preparation of liposomes}

Large unilamellar liposomes of pure dimyristoylphosphatidylcholine (DMPC from Sigma Belgium) were prepared by extrusion $[25,26]$. Lipid solutions in chloroform (HPLC grade, Merck, Belgium) were evaporated to dryness to form a thin layer of lipid. Phosphate buffer pH 7 (1/15 M; $\mathrm{Na}_{2} \mathrm{HPO}_{4}-\mathrm{KH}_{2} \mathrm{PO}_{4}$, from Riedel-de Haën, Belgium) or $\mathrm{D}_{2} \mathrm{O}$ (buffered $\mathrm{p} D$ 7.4, Sigma, Belgium) was added and the lipids were dispersed in buffer by vortexing. The resulting multilamellar liposome suspensions were extruded 8 times through a pile of two polycarbonate membrane filters (100 nm pore diameter, Whatman, USA) using an extruder device (Lipex Biomembranes, Vancouver, Canada). The large unilamellar liposomes were stored at $33{ }^{\circ} \mathrm{C}$ to avoid the fusion of liposomes, the phase transition temperature being $23{ }^{\circ} \mathrm{C}$ [27].

\subsection{Incorporation of PPF into liposomes}

The aim of this study was first to ascertain that under our experimental conditions for singlet oxygen studies, all PPF was incorporated in the liposomes. PPF (Acros, Belgium) was first dissolved in methanol (HPLC grade, Sigma, Belgium) to obtain stock solutions. A small volume $(5 \mu \mathrm{l})$ of the stock was added to the solutions $(1 \mathrm{ml})$ containing various amounts of liposomes to achieve the desired concentration of PPF. Under those conditions, the final percentage of methanol was $0.5 \%$ in all experiments. All the spectra of this study were recorded immediately after the mixing of PPF solutions with liposomes in the cell. When necessary, the samples were deaerated for $2 \mathrm{~h}$ under vacuum.

\subsection{Liposome binding constant, $K_{p}$, measurements}

A spectroscopic titration technique was used to quantify binding of PPF to the liposomes. The analytical binding constant, $K_{\mathrm{p}}$, was determined as follows [28]:

$K_{\mathrm{p}}=\frac{[\mathrm{PPF}]_{1}}{[\mathrm{PPF}]_{\mathrm{w}}[\mathrm{DMPC}]}$,

where $[\mathrm{PPF}]_{1},[\mathrm{PPF}]_{\mathrm{w}}$ and $[\mathrm{DMPC}]$ are the concentrations of PPF bound to the liposome or free in the bulk aqueous phase, and the phospholipid concentration, respectively. The constant $K_{\mathrm{p}}$ can be related to the fluorescence emission spectra of PPF by the following relation:

$F=\frac{F_{0}+K_{\mathrm{p}} F_{\infty}[\mathrm{DMPC}]}{1+K_{\mathrm{p}}[\mathrm{DMPC}]}$,

where $F_{0}$ and $F_{\infty}$ are the fluorescence intensities of PPF free in the bulk aqueous phase and totally bound to DMPC liposomes.

Eq. (2) can be modified as:

$\frac{1}{F-F_{0}}=\frac{1}{F_{\infty}-F_{0}}+\frac{1}{F_{\infty}-F_{0}} \frac{1}{K_{\mathrm{p}}} \frac{1}{[\mathrm{DMPC}]}$,

$K_{\mathrm{p}}$ is thus obtained by plotting $1 /\left(F-F_{0}\right)$ vs. $1 /$ [DMPC]. This representation is useful when $F_{\infty}$ cannot be attained experimentally.

\subsection{Fluorescence and absorption measurements}

The fluorescence emission spectra were recorded using a SLM-Aminco 500 pectrofluorimeter. The excitation was set at $266 \mathrm{~nm}$. 
The absorption spectra were recorded using a Kontron double beam spectrophotometer (Uvikon 941).

For both measurements, the solutions were placed in a quartz (Suprasil) cell of $0.4 \mathrm{~cm}$ width $\times 1 \mathrm{~cm}$ path length (Hellma, Belgium). The temperature was maintained at $33{ }^{\circ} \mathrm{C}$ during all measurements using water circulating around the cell.

\subsection{Continuous irradiation of the liposome solutions}

The irradiation of the RB (Eastman Kodak, USA) solutions was carried out using a slide projector (Pradovit RA 150, Leitz, Germany) as a light source. The halogen lamp (Xenophot $150 \mathrm{~W}, 24 \mathrm{~V}$, Osram, Belgium) output was passed through a GG 475 filter (Schott, Germany) to select wavelengths above $475 \mathrm{~nm}$. Solutions were placed at a distance of $11 \mathrm{~cm}$ from the projector. Under those conditions, the total volume of the solution was homogeneously irradiated.

\subsection{HPLC measurements}

HPLC measurements were performed to characterize the oxidation products formed during the irradiation of a $\mathrm{RB}$ $\left(8 \times 10^{-6} \mathrm{M}\right)$ solution, in the presence of PPF $\left(5 \times 10^{-4} \mathrm{M}\right)$ totally bound to the liposomes $\left(2.2 \times 10^{-2} \mathrm{M}\right)$. When necessary, liposomes were dissolved in $\mathrm{D}_{2} \mathrm{O}$ instead of phosphate buffer $\mathrm{pH}$ 7. During competition experiments, $\mathrm{NaN}_{3}\left(10^{-1} \mathrm{M}\right.$, Sigma, Belgium) was added to the solution. In our experiments, solutions were injected without any treatment on a column cc 250/4.4 mm Nucleosil 100-5 C18 (Macherey-Nagel, Düren, Germany). HPLC analyses were performed on a Merck-Hitachi L7000 (LaChrom, Merck, Belgium) fitted with a Merck-Hitachi L7400 UV-visible detector. We used a linear gradient from 0 to $100 \%$ of solvent B (trifluoroacetic acid/acetonitrile/methanol/water, 0.05:50:10:40) in solvent A (trifluoroacetic acid/acetonitrile/ water: $0.05: 35: 65$ ) for $60 \mathrm{~min}$ followed by an isocratic elution with solvent B for $25 \mathrm{~min}$. The flow rate was $1 \mathrm{ml}$ $\min ^{-1}$. All the solvents used as mobile phase were of HPLC grade and purchased from Sigma (Belgium).

\subsection{Time resolved detection of ${ }^{1} \mathrm{O}_{2}$ infrared luminescence}

In this paper, $k_{\mathrm{PPF}}$ was noted as the global rate constant for both the physical and chemical quenching of ${ }^{1} \mathrm{O}_{2}$ by PPF. The determination of the $k_{\mathrm{PPF}}$ value was based on the time-resolved detection of the ${ }^{1} \mathrm{O}_{2}$. The luminescence spectrometer used for these studies has been previously described in detail [22]. Briefly, a Quantel Nd/Yag laser was used as the excitation light. The wavelength of excitation was $532 \mathrm{~nm}$ and the solutions were placed in a Suprasil quartz cell $(1 \mathrm{~cm} \times 1 \mathrm{~cm})$. The ${ }^{1} \mathrm{O}_{2}$ luminescence was measured at $1270 \mathrm{~nm}$ and an average of eight shots was used to get a good signal-to-noise ratio. In all cases, solutions were air saturated, thermostated at $33{ }^{\circ} \mathrm{C}$ and hand mixed before each laser shot. The two photosensitizers, uroporphyrin I (UP, Frontier scientific, USA) and deuteroporphyrin (DP), which was prepared and purified as previously described [28], were used as ${ }^{1} \mathrm{O}_{2}$ source. They were chosen because the former is located in the aqueous $\left(\mathrm{D}_{2} \mathrm{O}\right)$ phase $[29,30]$ while the latter is embedded in the liposome membrane [31]. The association constant of DP for DMPC liposomes (diameter, $100 \mathrm{~nm}$ ) was found to be $(12 \pm 2) \times 10^{4} \mathrm{M}^{-1}$ [31]. Then, total incorporation of DP within the liposomes was ensured by using a $2.2 \times 10^{-2} \mathrm{M}$ DMPC concentration. In order to get an ${ }^{1} \mathrm{O}_{2}$ lifetime long enough to be measured, liposomes were dispersed in $\mathrm{D}_{2} \mathrm{O}$. The $\mathrm{p} D$ of the $\mathrm{D}_{2} \mathrm{O}$ solution was adjusted to 7.4, which corresponds to a $\mathrm{pH}$ value of 7.0 in water [32]. Solutions with absorbances of about 0.4 at $532 \mathrm{~nm}$ were employed.

The high concentration of DMPC used in the present experiments led to scattering, which could not be completely removed by the optical filter placed on the detection path and thus affected the signal observed at $1270 \mathrm{~nm}$ after the laser pulse. The contribution of the scattering signal was assessed from a solution that contained liposomes only. It was well fitted by a monoexponential curve. This artifact signal was subtracted from that obtained in the presence of the photosensitizer, allowing the observation of ${ }^{1} \mathrm{O}_{2}$. The corrected signal was nicely fitted by monoexponetial curves yielding the lifetime of ${ }^{1} \mathrm{O}_{2}$.

\subsection{Cell culture}

Neuro 2a cells, a subclone of the C1300 murine neuroblastoma derived spontaneously in the $\mathrm{A} / \mathrm{J}$ mouse (from American Type Culture Collection, Rockville, USA), were cultured in Dulbecco's modified Eagle's medium (DMEM, Gybco, Belgium) supplemented with 5\% foetal calf serum (from Gybco, Belgium), $2 \mathrm{mM}$ L-glutamine (from Gybco, Belgium), $0.01 \%$ penicillin-streptomycin (from Gybco, Belgium), and $0.002 \%$ gentamicin (from Gybco, Belgium) and were maintained in a humidified $37{ }^{\circ} \mathrm{C}, 5 \% \mathrm{CO}_{2}$ incubator.

Throughout the whole in vitro experiment, the PPF solutions were freshly prepared by dissolving in PBS/ ethanol mixture to a concentration of $10^{-3} \mathrm{M}$ and further diluted in the culture medium. The control cultures were treated with an equivalent concentration of ethanol alone, which, up to the highest dose $(0.1 \%)$, had no effect on cell viability. The RB solutions were prepared by dissolving in PBS to a concentration of $10^{-4} \mathrm{M}$.

The sensitivity of the neuro 2 a cells to PPF or RB nonirradiated was determined in vitro by trypan blue exclusion essay. Briefly, 15000 cells were seeded in triplicate wells in a 24-well microtiter plate, $24 \mathrm{~h}$ prior to the drug treatment. The cells were exposed to increasing concentrations $(0,1$, 10 , and $100 \mu \mathrm{M})$ of PPF or RB non-irradiated $(0,1,10$, and $50 \mu \mathrm{M}$ ) for 24 or $48 \mathrm{~h}$. Cell viability was then determined by trypan blue dye exclusion essay. 
The neuroprotective activity of PPF to prevent cellular death induced by ${ }^{1} \mathrm{O}_{2}$ produced by the photosensitization of $\mathrm{RB}$ was determined in vitro by the study of the cell viability. Briefly, cells were plated in culture 24-well microtiter plate at a density of 57,000 cells $/ \mathrm{cm}^{2}, 24 \mathrm{~h}$ prior to the drug treatment. The cells were then exposed to increasing concentrations of PPF $(0,50$, and $100 \mu \mathrm{M})$ for $24 \mathrm{~h}$. After treatment, the culture medium was removed and replaced by HBSS buffer. RB was further added to the cells in order to reach a concentration of $10 \mu \mathrm{M}$. Moreover, PPF $(100 \mu \mathrm{M})$ was added simultaneously with RB in some wells not previously treated by the drug. Further, the whole 24microtiter plate was irradiated for 5 min with an experimental lamp $\left(\lambda_{\max }=560 \mathrm{~nm}\right.$, Vanhoven-Evrad, Belgium). This experimental lamp ensures an identical luminous intensity in any point of the microtiter plate. After irradiation, the buffer was removed and replaced by culture medium. The cells were then incubated at $37{ }^{\circ} \mathrm{C}$ for $1 \mathrm{~h}$ in a humidified atmosphere with $5 \%$ of $\mathrm{CO}_{2}$. The cell viability was determined by trypan blue dye exclusion essay.

All data were presented as means \pm S.E. of 8 independent experiments. Statistical analysis was performed using an analysis of variance (one-way ANOVA). The accepted level of significance was $P \leq 0.05$. Statistical differences between groups were analysed using Tukey test.

\section{Results}

\subsection{Interaction of PPF with DMPC liposomes}

Before dealing with systems involving liposomes, the solution behaviour of PPF was examined. In phosphate buffer, PPF exhibited absorption and emission spectra characteristic of monomeric forms over a wide range of concentrations (from $10^{-5} \mathrm{M}$ to $8 \times 10^{-4} \mathrm{M}$ ). The fluorescence maximum of PPF is located at $305 \mathrm{~nm}$. Fig. 1 shows that the gradual addition of preformed liposomes to PPF $\left(10^{-5} \mathrm{M}\right)$ aqueous solutions leads to an increase in the maximum fluorescence intensity of the anaesthetic agent, suggesting the binding of PPF to liposomes. This binding was found to proceed within less than $1 \mathrm{~min}$ and no significant further changes in fluorescence spectra took place over hours.

In order to quantify the binding of PPF to the liposomes, an analytical binding constant $\left(K_{\mathrm{p}}\right)$ was evaluated by recording the fluorescence emission spectra of the solutions with various lipid concentrations (from 0 to $1.25 \times 10^{-3} \mathrm{M}$ ) with a constant PPF concentration of $10^{-5} \mathrm{M}$. According to Eq. (3), the fluorescence titration of PPF with DMPC liposomes was represented in the inset of Fig. 1, from which we estimated the binding constant $K_{\mathrm{p}}=(0.72 \pm 0.12) \times 10^{4}$ $\mathrm{M}^{-1}$ at $\mathrm{pH} 7$ and $33{ }^{\circ} \mathrm{C}$. From Eq. (1), it can be calculated that at a DMPC concentration equal to $2.2 \times 10^{-2} \mathrm{M}, 99.4 \%$ of PPF is associated to the liposomes. This DMPC concentration was used in all further experiments.

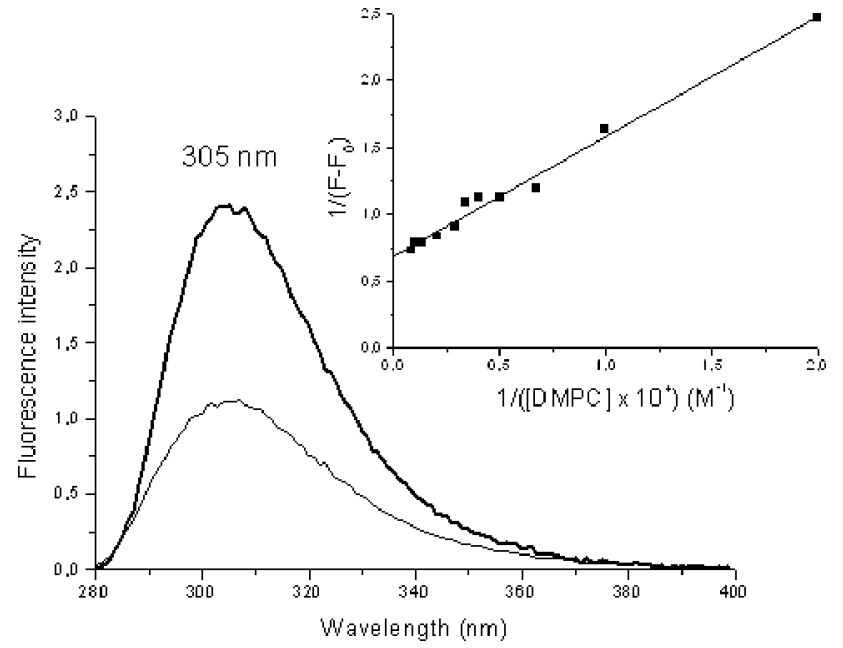

Fig. 1. Emission spectra $\left(\lambda_{\mathrm{exc}}=266 \mathrm{~nm}\right)$ of PPF $\left(10^{-5} \mathrm{M}\right)$ at $33{ }^{\circ} \mathrm{C}$ in the absence (thin line) or presence of DMPC $\left(10^{-3} \mathrm{M}\right)$ liposomes (thick line) made in phosphate buffer $(\mathrm{pH} 7)$. The inset represents $1 /\left(F-F_{0}\right)$ in the function of $1 /$ [DMPC] and the theoretical curve drawn according to Eq. (3).

\subsection{Reactivity of $P P F$ with ${ }^{1} \mathrm{O}_{2}$}

To characterize the interaction of ${ }^{1} \mathrm{O}_{2}$ with PPF bound to the liposomes, near-IR luminescence measurements were made. PPF bound to liposomes quenches the luminescence decay of ${ }^{1} \mathrm{O}_{2}$ (Fig. 2, inset), indicating that PPF reacts with this reactive oxygen species. As shown in Fig. 2, the ${ }^{1} \mathrm{O}_{2}$ rate constant of PPF was estimated by the Stern-Volmer-type quenching curves of ${ }^{1} \mathrm{O}_{2}$ lifetime, the latter depending on the nature of the sensitizer, $(1.35 \pm 0.05) \times 10^{7} \quad \mathrm{M}^{-1} \mathrm{~s}^{-1}$ and $(0.8 \pm 0.04) \times 10^{7} \mathrm{M}^{-1}$ $\mathrm{s}^{-1}$, when the ${ }^{1} \mathrm{O}_{2}$ sources were deuteroporphyrin (DP) and uroporphyrin (UP), respectively. It must be noted that the constants thus determined are not the "true" quenching constants but composites of the "true" quenching in the bilayer and the rate constants for the entrance to and exit of ${ }^{1} \mathrm{O}_{2}$ from the vesicles.

\subsection{Oxidation products of $P P F$}

Fig. 3a shows the absorption spectrum of the PPF oxidation product resulting from the reaction with ${ }^{1} \mathrm{O}_{2}$, produced by the irradiation of the xanthene dye Rose Bengal (RB) [33], as followed at $424 \mathrm{~nm}$. Two experiments were carried out in order to ascertain whether this reaction really occurs. The first one was made in the presence of sodium azide $\left(\mathrm{NaN}_{3}\right)$, a well-known ${ }^{1} \mathrm{O}_{2}$ quencher [34], and the second one in $\mathrm{D}_{2} \mathrm{O}$, known to increase the ${ }^{1} \mathrm{O}_{2}$ lifetime [35]. When the experiments were performed in the presence of $\mathrm{NaN}_{3}$ (from $10^{-2} \mathrm{M}$ to $10^{-1} \mathrm{M}$ ), a strong decrease of the oxidation product was observed (Fig. 3b). Likewise, the use of $\mathrm{D}_{2} \mathrm{O}$ instead of the phosphate buffer led to a decrease of oxidation product (Fig. 3b).

On Fig. 3c, a correlation was found between the number of PPF molecules bound to liposomes and the formation of the oxidation product. Consequently, by increasing the 

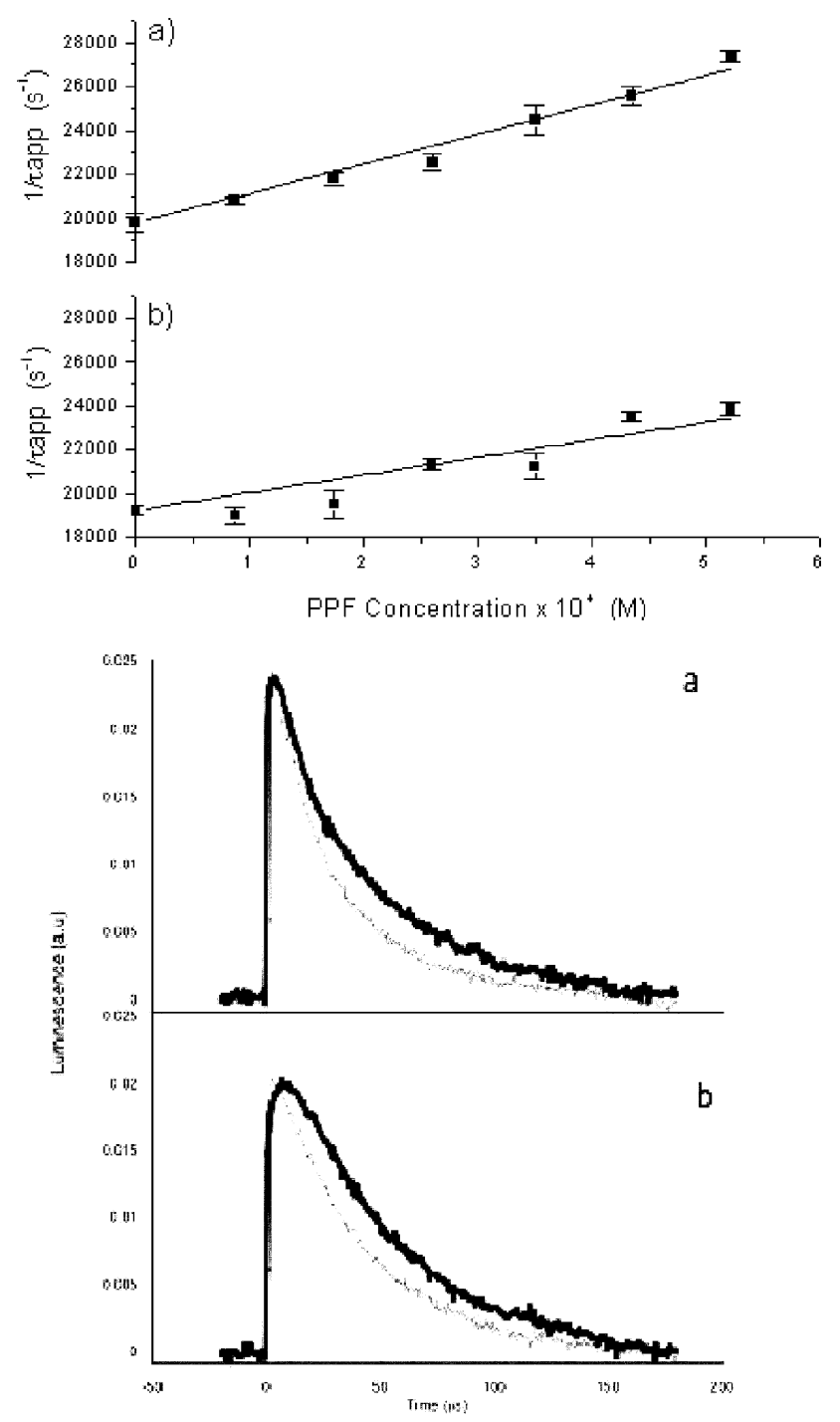

Fig. 2. Stern-Volmer data of the quenching of singlet oxygen generated by deuteroporphyrin (a) or uroporphyrin (b) in a DMPC $\left(2.2 \times 10^{-2} \mathrm{M}\right)$ liposomes $/ \mathrm{D}_{2} \mathrm{O}$ mixture. The suspensions contained varying ratio of PPF. The inset represents the decay of ${ }^{1} \mathrm{O}_{2}$ luminescence in the absence (thick) or presence (thin) of PPF with deuteroporphyrin (a) or uroporphyrin (b) as ${ }^{1} \mathrm{O}_{2}$ source.

concentration ratio between DMPC and PPF while keeping the PPF concentration constant, a decrease of the intensity of the peak absorbance, located at $424 \mathrm{~nm}$, was observed.

In contrast to the absorption experiments, the HPLC measurements showed the appearance of another oxidation product from PPF with a retention time of $45.05 \mathrm{~min}$. This product was inhibited in the presence of $10^{-1} \mathrm{M} \mathrm{NaN}_{3}$ and enhanced when the experiment was made in $\mathrm{D}_{2} \mathrm{O}$ (Fig. 4).

\subsection{Effect of PPF on the neuronal cell toxicity induced by ${ }^{1} \mathrm{O}_{2}$}

Initial experiments were set up to evaluate the toxicity of PPF toward neuronal cells. Fig. 5a shows that the preincubation of PPF at the concentration ranging from 1 to $100 \mu \mathrm{M}$, for several hours, did not induce any toxic effect. Likewise, before dealing with the neuroprotective action of PPF, the potential toxicity of RB on neuronal cells was assessed. At the concentration used to produce ${ }^{1} \mathrm{O}_{2}$, no toxic effect was observed (data not shown). We chose the
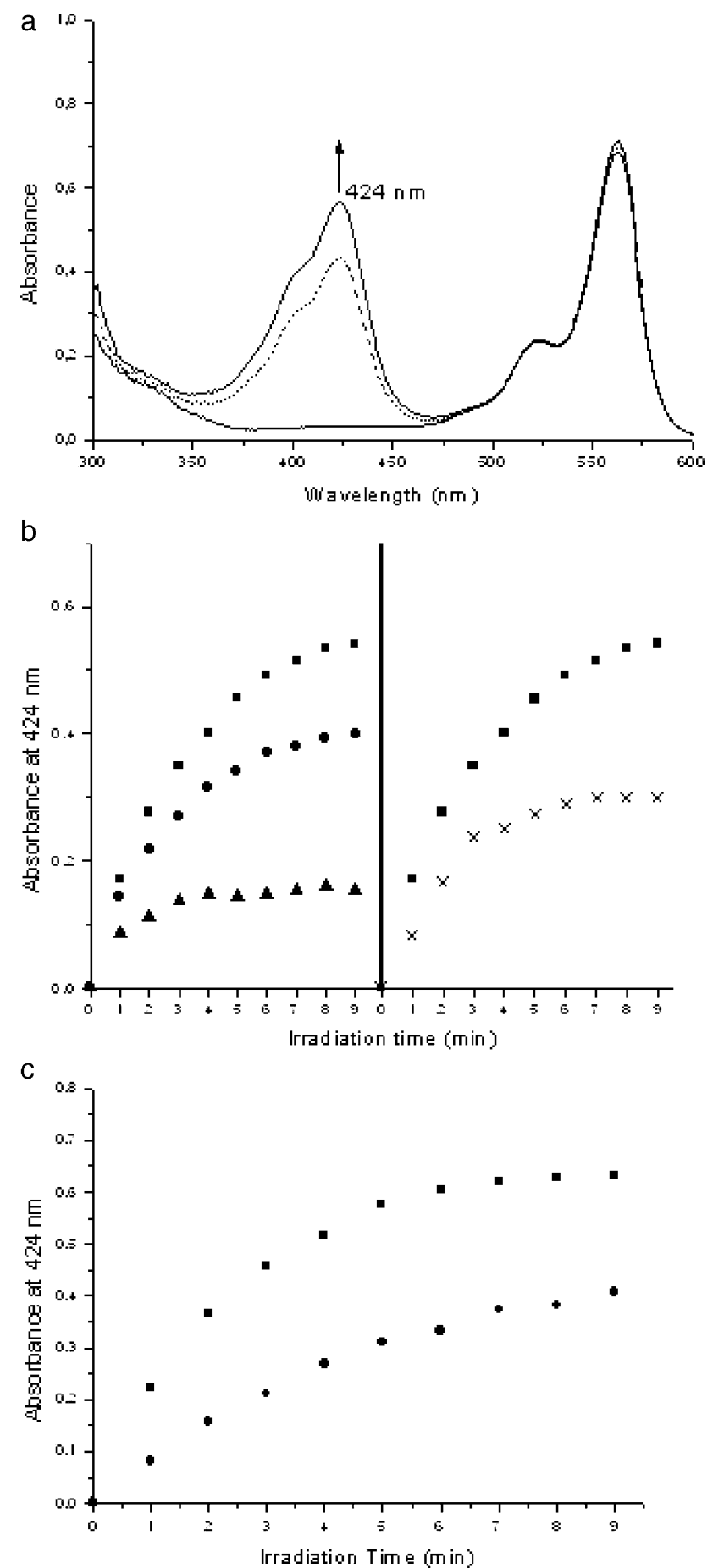

Fig. 3. Absorption of an aerated RB solution $\left(8 \times 10^{-6} \mathrm{M}\right)$, irradiated $(\lambda>475 \mathrm{~nm})$ in the presence of $2.2 \times 10^{-2} \mathrm{M}$ DMPC liposomes and $5 \times 10^{-4}$ M PPF. (a) Spectrum obtained after 0, 4, and 8 min, respectively. (b) Value measured at $424 \mathrm{~nm}:(\square)$ in phosphate buffer $(\mathrm{pH} 7) ;(\bullet)$ in the presence of $10^{-2} \mathrm{M} \mathrm{NaN}_{3} ;(\boldsymbol{\Delta})$ in the presence of $10^{-1} \mathrm{M} \mathrm{NaN}_{3} ;(\times)$ in $\mathrm{D}_{2} \mathrm{O}$. (c) Value measured at $424 \mathrm{~nm}$ for a lipid to PPF ratio equal to (ロ) 44 and (•) 120 . 


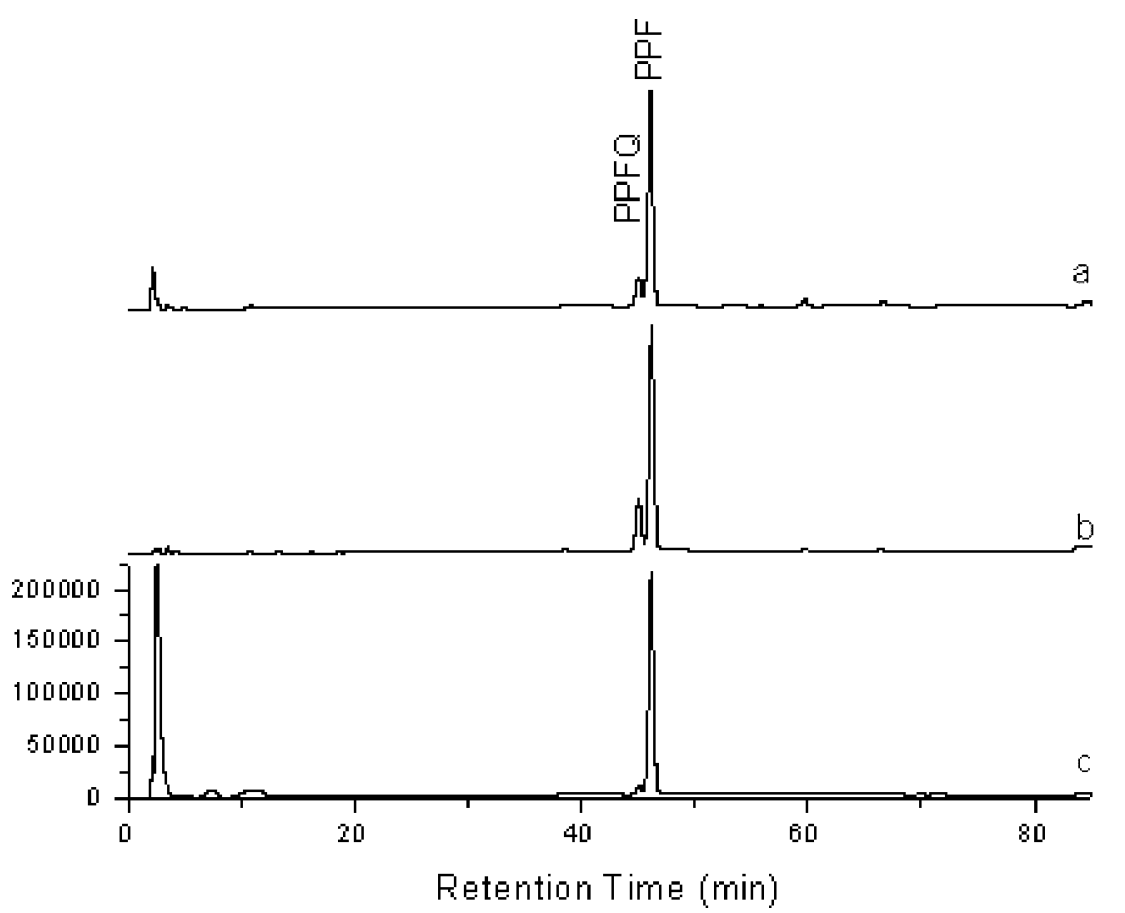

Fig. 4. HPLC chromatographic analysis of an irradiated $(10 \mathrm{~min}) \mathrm{RB}\left(8 \times 10^{-6} \mathrm{M}\right)$ solution in the presence of $2.2 \times 10^{-2} \mathrm{M}$ DMPC liposomes and $5 \times 10^{-4} \mathrm{M}$ $\mathrm{PPF}$, in aerated condition: (a) in phosphate buffer; (b) $\mathrm{D}_{2} \mathrm{O}$; (c) in phosphate buffer with the addition of $10^{-1} \mathrm{M} \mathrm{NaN}_{3}$.

irradiation of Rose Bengal (RB) as a mean of generating ${ }^{1} \mathrm{O}_{2}$ in cells since this reaction system is easily controlled, ensuring a constant production of ${ }^{1} \mathrm{O}_{2}$, and because the irradiation of RB is known to induce a cytotoxic effect due to ${ }^{1} \mathrm{O}_{2}$ production $[36,37]$.

Neuronal cells preincubated with PPF $(50 \mu \mathrm{M}$ and $100 \mu \mathrm{M})$ were irradiated in the presence of $10 \mu \mathrm{M} \mathrm{RB}$ and showed a significant increase $(P<0.05, n=8)$ of cell viability (Fig. 5b). This protective effect exerted in a concentration-dependent manner and was correlated with the penetration of PPF within cells.

\section{Discussion}

In the present work, we have studied the interaction of PPF with liposomes used as membrane models. PPF was found to bind liposomes as shown by fluorescence measurements. A close correlation was indeed observed between the increase of the peak intensity of PPF fluorescence and the increasing amount of preformed liposomes.

The ${ }^{1} \mathrm{O}_{2}$ near-IR luminescence measurements give new insight to characterize the binding of PPF to the lipid membrane. These results indicate an embedding of the anaesthetic agent within the liposomes. Indeed, we obtained different values for the ${ }^{1} \mathrm{O}_{2}$ quenching rate constant of PPF $\left(k_{\mathrm{PPF}}\right)$ as a function of the location of the ${ }^{1} \mathrm{O}_{2}$ source, reflecting changes in the local concentration of ${ }^{1} \mathrm{O}_{2}$ relative to the $\mathrm{OH}$ group of PPF $[38,39]$. These values are $(1.35 \pm 0.05) \times 10^{7} \mathrm{M}^{-1} \mathrm{~s}^{-1}$ for DP, which is embedded within the liposomes [31], and $(0.8 \pm 0.04) \times 10^{7} \mathrm{M}^{-1} \mathrm{~s}^{-1}$ for the aqueous dye, UP $[29,30]$. The large quenching rate constant obtained for DP compared to UP implies that PPF must be embedded within the liposome. Indeed, if PPF is well embedded within the liposome, in the DP system, ${ }^{1} \mathrm{O}_{2}$ is generated and mainly distributed in the lipid bilayer because of the higher solubility of ${ }^{1} \mathrm{O}_{2}$ in this medium [40], which is characterized by a high PPF concentration. Thus, the reaction between ${ }^{1} \mathrm{O}_{2}$ and PPF takes place before ${ }^{1} \mathrm{O}_{2}$ can substantially diffuse into the solution. On the other hand, as UP system generates ${ }^{1} \mathrm{O}_{2}$ in the aqueous surrounding environment, where the PPF concentration is negligible, ${ }^{1} \mathrm{O}_{2}$ has to diffuse from the solution into the membrane before quenching takes place, resulting thus in a lower value for $k_{\mathrm{PPF}}$ in this system.

These results are in agreement with the literature data about PPF [41,42], as well as our recent findings obtained by electronic spin resonance spectroscopy [43], indicating that PPF possesses a diffused position in the whole region of the acyl chain.

We demonstrated that ${ }^{1} \mathrm{O}_{2}$ produced by photosensitization in a lipid environment reacted with PPF to yield two PPF by-products. By comparison with authentic samples [22], the product which absorbs at $424 \mathrm{~nm}$ is identified as PPFDQ (3,5,3', $5^{\prime}$-tetraisopropyl-(4,4')-diphenoquinone) and the other one detected by HPLC $\left(R_{\mathrm{t}}=45.05 \mathrm{~min}\right)$ is identified as PPFQ (2,6-diisopropyl-p-benzoquinone).

These two by-products are the oxidation products of PPF resulting from the reactions between $\mathrm{PPF}$ and ${ }^{1} \mathrm{O}_{2}$ since they are formed exclusively in the simultaneous presence of the irradiated photosensitizer (RB) and oxygen. In addition, the measurements carried out in the presence of $\mathrm{NaN}_{3}$, a ${ }^{1} \mathrm{O}_{2}$ 

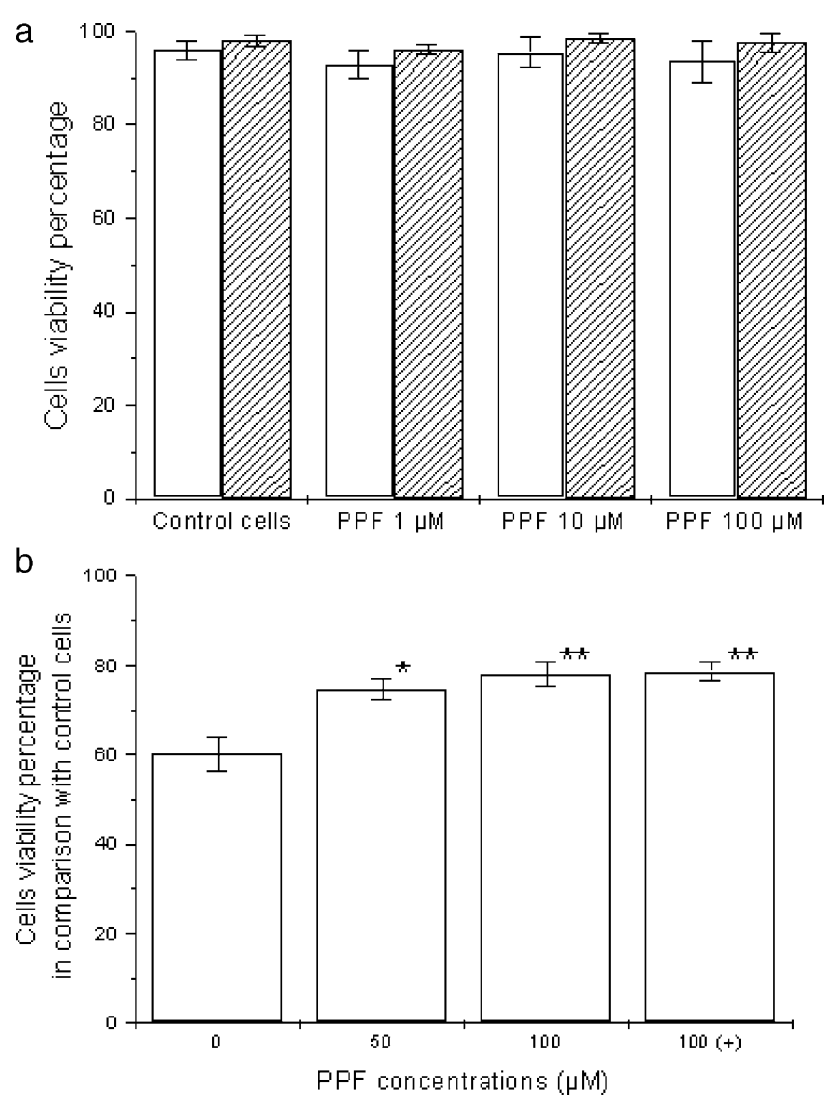

Fig. 5. (a) Mean ( \pm S.E.) of living cells percentage in the absence (control) or presence of increasing PPF concentrations after 24 (white) or 48 (////) h. (b) Mean $( \pm$ S.E. $)$ of the percentage of living cells, in comparison with control cells, exposed to irradiated RB $(10 \mu \mathrm{M})$ for $5 \mathrm{~min}$, in the absence or presence of PPF $(50 \mu \mathrm{M}-100 \mu \mathrm{M})$. The control cells correspond to cells irradiated without RB nor PPF. The symbol $(+)$ means that the cells were not treated prior with PPF and then that the anaesthetic agent was added just before the irradiation. $*$ The results are significant $(P<0.05) ; * *$ the results are highly significant $(P<0.01)$.

quencher [34], demonstrated a significant decrease of the PPF by-products, indicating the pivotal role played by ${ }^{1} \mathrm{O}_{2}$ in the conversion of PPF. On the other hand, the result obtained when $\mathrm{D}_{2} \mathrm{O}$ is used instead of phosphate buffer must be emphasized. Indeed, the increase of ${ }^{1} \mathrm{O}_{2}$ lifetime by the use of $\mathrm{D}_{2} \mathrm{O}$ instead of phosphate buffer should lead to an increase of the PPF by-products. However, while an increase is well observed for PPFQ, a decrease of PPFDQ is obtained. This is reminiscent of the results obtained in our previous study made in aqueous solutions [22]. However, as also reported in our previous study, this reducing effect does not result from a direct interaction between ${ }^{1} \mathrm{O}_{2}$ and PPFDQ. Indeed, in preliminary experiments, we observed that the absorption spectrum of authentic PPFDQ solution in the presence of preformed liposomes remains unchanged both in shape and in maximum intensity, in the absence or presence of ${ }^{1} \mathrm{O}_{2}$ produced by photosensitization.

Conclusively, the nature and the behaviour of the oxidation products of PPF being the same in the lipid environment as in solutions, we propose the same reaction scheme than in our previous work [22], relative to aqueous solutions, to account for the whole set of experiments reported. According to this reaction scheme, the reaction between PPF and ${ }^{1} \mathrm{O}_{2}$ involves the formation of the PPF phenoxyl radical as an intermediate. This radical species undergo a dimerization to give a diphenol derivative which is further oxidized to form PPFDQ. On the other hand, the phenoxyl radical can also react with both fundamental and singlet oxygen to give PPFQ.

Diffusion of $\mathrm{PPF}^{*}$ within the liposomes to form PPFDQ is evidenced by the fact that the increase of the DMPC/PPF ratio, while PPF concentration is kept constant, leads to a decrease in PPFDQ formation. On the other hand, the formation of PPFQ by the interaction between oxygen and phenoxyl radical is well known for phenolic compounds but is yet less effective than the dimerization of the phenoxyl radical [44].

The original results reported in this study offer an interesting prospect regarding the role that PPF could play in biological systems. In fact, PPF seems to be a potent ${ }^{1} \mathrm{O}_{2}$ inhibitor, with an efficient ability to penetrate membranes. Thus, the location of the anaesthetic agent in membranes increases its local concentration and may be sufficient to allow PPF to protect neuronal cells from ${ }^{1} \mathrm{O}_{2}$ damage.

In order to gain insight into the potential protective effect of PPF on neuronal cells, we also examined in this study the neuroprotective effects of PPF on cell death induced by ${ }^{1} \mathrm{O}_{2}$. We have demonstrated that PPF, at anaesthetically relevant concentrations [15], exerts protective effects on neuronal cells, as manifested in a significant enhancement of the cell viability towards damage induced by ${ }^{1} \mathrm{O}_{2}$. Moreover, the antioxidant effect of PPF was found to be immediate and was in agreement with recent data obtained on an in vitro cell model [16].

Consequently, the present results provide experimental support for investigating the potential benefit of using PPF as an anaesthetic drug for patients subjected to ischemic situations, in which a large amount of ${ }^{1} \mathrm{O}_{2}$ can be produced, leading to cell damage. If the use of PPF as antioxidant, in the clinical situations, may appear an exciting goal for the anaesthetist, it seems, however, that numerous concerns regarding the potential toxic effects of its by-products remain to be elucidated and further examinations are needed.

\section{Acknowledgements}

This work was supported by the CGRI-CNRS-FNRS funds.

\section{References}

[1] B.R. Lucchesi, Myocardial ischemia, reperfusion and free radical injury, Am. J. Cardiol. 65 (1990) 14I-23I.

[2] M.J. Steinbeck, A.U. Khan, M.J. Karnovsky, Intracellular singlet 
oxygen generation by phagocytosing neutrophils in response to particles coated with a chemical trap, J. Biol. Chem. 267 (1992) $13425-13433$.

[3] T.W. Stief, The physiology and pharmacology of singlet oxygen, Med. Hypotheses 60 (2003) 567-572.

[4] C. Kiryu, M. Makiuchi, J. Miyazaki, T. Fujinaga, K. Kakinuma, Physiological production of singlet molecular oxygen in the myeloperoxidase $-\mathrm{H}_{2} \mathrm{O}_{2}-$ chloride system, FEBS Lett. 443 (1999) 154-158.

[5] B. Halliwell, J.M.C. Gutteridge, Free Radicals in Biology and Medicine, second edition, Oxford Univ. Press, New York, 1989.

[6] K. Briviba, L.-O. Klotz, H. Sies, Toxic and signaling effect of photochemically or chemically generated singlet oxygen in biological systems, Biol. Chem. 378 (1997) 1259-1265.

[7] M.-C. Toufektsian, F.R. Boucher, S. Tanguy, S. Morel, J.G. De Leiris, Cardiac toxicity of singlet oxygen: implication in reperfusion injury, Antioxid. Redox Signal. 3 (2001) 63-69.

[8] X. Zhai, M. Ashraf, Direct detection and quantification of singlet oxygen during ischemia and reperfusion in rat hearts, Am. J. Physiol. 269 (1995) H1229-H1236.

[9] R.J. Wagner, P.A. Motchnik, R. Stocker, H. Sies, B.N. Ames, The oxidation of blood plasma and low density lipoprotein components by chemically generated singlet oxygen, J. Biol. Chem. 268 (1993) $18502-18506$

[10] J. Piette, Biological consequences associated with DNA oxidation mediated by singlet oxygen, J. Photochem. Photobiol., B Biol. 11 (1991) 241-260.

[11] M.J. Davies, Singlet oxygen-mediated damage to proteins and its consequences, Biochem. Biophys. Res. Commun. 305 (2003) $761-770$.

[12] H.M. Bryson, B.R. Fulton, D. Faulds, Propofol: an update of its use in anaesthesia and conscious sedation, Drugs 50 (1995) 513-559.

[13] D.L. Weir, C.S. Goodchild, D.I. Graham, Propofol: effects on indices of cerebral ischemia, J. Neurosurg. Anesthesiol. 1 (1989) 284-289.

[14] O. Eriksson, P. Pollesello, N.-E. Leo Saris, Inhibition of lipid peroxidation in isolated rat liver mitochondria by general anaesthetic propofol, Biochem. Pharmacol. 44 (1992) 391-393.

[15] P. Hans, C. Deby, G. Deby-Dupont, B. Vrijens, A. Albert, M. Lamy, Effect of propofol on in vitro lipid peroxidation induced by different free radical generating systems: a comparison with vitamin E, J. Neurosurg. Anesthesiol. 8 (1996) 154-158.

[16] J.P. De la Cruz, G. Sedeno, J.A. Carmona, F. Sanchez de la Cuesta, The in vitro effects of propofol on tissular oxidative stress in the rat, Anesth. Anal. 87 (1998) 1141-1146.

[17] A. Mouithys-Mickalad, P. Hans, G. Deby-Dupont, M. Hoebeke, C. Deby, M. Lamy, Propofol reacts with peroxynitrite to form a phenoxyl radical: demonstration by electron spin resonance, Biochem. Biophys. Res. Commun. 249 (1998) 833-837.

[18] S.L. Kohnen, A.A. Mouithys-Mickalad, G.P. Deby-Dupont, C.M.T. Deby, P. Hans, M.L. Lamy, A.F. Noels, Investigation of the reaction of peroxynitrite with propofol at acid $\mathrm{pH}$ : predominant production of oxidized, nitrated and halogenated derivatives, Nitric Oxide 8 (2003) $170-181$.

[19] S. Nonell, L. Moncayo, F. Trull, F. Amat-Guerri, E.A. Lissi, A.T. Soltermann, S. Criado, N.A. Garcia, Solvent influence on the kinetics of the photodynamic degradation of Trolox, a water-soluble model compound for vitamin E, J. Photochem. Photobiol., B Biol. 29 (1995) $157-162$.

[20] C.R. Lambert, H.S. Black, G. Truscott, Reactivity of butylated hydroxytoluene, Free Radic. Biol. Med. 21 (1996) 395-400.

[21] M. Luiz, M.I. Gutiérrez, G. Bocco, N.A. Garcia, Solvent effect on the reactivity of monosubstituted phenols towards singlet molecular oxygen $\mathrm{O}_{2}\left({ }^{1} \Delta_{2}\right)$ in alkaline media, Can. J. Chem. 71 (1993) $1247-1252$.

[22] B. Heyne, S. Kohnen, D. Brault, A. Mouihys-Mickalad, F. Tfibel, P. Hans, M.-P. Fontaine-Aupart, M. Hoebeke, Investigation of singlet oxygen reactivity towards propofol, Photochem. Photobiol. Sci. 2 (2003) 939-945.
[23] P.G. Murphy, J.R. Bennet, D.S. Myers, M.J. Davies, J.G. Jones, The effect of propofol anaesthesia on free radical-induced lipid peroxidation in rat liver microsomes, Eur. J. Anaesthesiol. 10 (1993) 261 - 266.

[24] M. Hoebeke, The importance of liposomes as models and tools in the understanding of photosensitization mechanisms, J. Photochem. Photobiol., B Biol. 28 (1995) 189-196.

[25] M.J. Hope, M.B. Bally, G. Web, P.R. Cullis, Production of large unilamellar vesicles by rapid extrusion procedure. Characterization of size distribution, trapped volume and ability to maintain a membrane potential, Biochem. Biophys. Acta 812 (1985) 55-65.

[26] L. Mayer, M. Hope, P. Cullis, Vesicles of variable sizes produced by rapid extrusion procedure, Biochem. Biophys. Acta 858 (1986) $161-168$.

[27] G.S. Dixon, S.G. Black, C.T. Butler, A.K. Jain, A differential a.c. calorimeter for biophysical studies, Anal. Biochem. 121 (1982) 55-61.

[28] D. Brault, C. Vever-Bizet, T. Le Doan, Spectrofluorimetric study of porphyrin incorporation into membrane models-evidence for $\mathrm{pH}$ effects, Biochem. Biophys. Acta 857 (1986) 238-250.

[29] F. Ricchelli, G. Jori, Distribution of porphyrins in the various compartments of unilamellar liposomes of dipalmitoyl-phosphatidylcholine as probed by fluorescence spectroscopy, Photochem. Photobiol. 44 (1986) 151-157.

[30] C. Emiliani, M. Delmelle, The lipid solubility of porphyrins modulates their phototoxicity in membrane models, Photochem. Photobiol. 37 (1983) 487-490.

[31] K. Kuzelova, D. Brault, Kinetic and equilibrium studies of porphyrin interactions with unilamellar lipidic vesicles, Biochemistry 33 (1994) 9447-9459.

[32] P. Salomaa, L. Schaleger, F.A. Long, Solvent deuterium isotope effect on acid-base equilibria, J. Am. Chem. Soc. 86 (1964) 1-7.

[33] E. Gandin, Y. Lion, A. Van de Vorst, Quantum yield of singlet oxygen production by xanthene derivatives, Photochem. Photobiol. 37 (1983) 271-278.

[34] N. Hasty, P.B. Merkel, P. Radlick, D.R. Kearns, Role of azide in singlet oxygen reactions: reaction of azide with singlet oxygen, Tetrahedron. Lett. 1 (1972) 9-52.

[35] M.A.J. Rodgers, Solvent-induced deactivation of singlet oxygen: additivity relationships in nonaromatic solvents, J. Am. Chem. Soc. 105 (1983) 6201-6205.

[36] A.J.W. Huang, B.D. Watson, E. Hernandez, S.C.G. Tseng, Photothrombosis of corneal neovascularization by intravenous Rose Bengal and argon laser irradiation, Arch. Ophtalmol. 106 (1988) 680-685.

[37] D.P. Valenzeno, J. Trudgen, A. Hutzenbuhler, M. Milne, Singlet oxygen involvement in photohemolysis sensitized by merocyanine540 and Rose Bengal, Photochem. Photobiol. 46 (1987) 985-990.

[38] A. Vilensky, J. Feitelson, Reactivity of singlet oxygen with tryptophan residues and with melittin in liposome systems, Photochem. Photobiol. 70 (1999) 841-846.

[39] K. Fukuzawa, K. Matsuura, A. Tokumura, A. Suzuki, J. Terao, Kinetics and dynamics of singlet oxygen scavenging by $\alpha$-tocophenol in phospholipid model membranes, Free Radic. Biol. Med. 22 (1997) 923-930.

[40] E.S. Smotkin, F.T. Moy, W.Z. Plachy, Dioxygen solubility in aqueous phosphatidylcholine dispersions, Biochem. Biophys. Acta 1061 (1991) 33-38.

[41] H. Tsuchiya, Structure-specific membrane-fluidizing effect of propofol, Clin. Exp. Pharmacol. Physiol. 28 (2001) 292-299.

[42] F. Momo, S. Fabris, A. Wisniewska, C. Fiore, A. Bindoli, G. Scutari, R. Stevanato, Correlation between fluidising effects on phospholipid membranes and mitochondrial respiration of propofol and $p$-nitrosophenol homologues, Biophys. Chem. 103 (2003) 213-222.

[43] A.B. Bahri, B.J. Heyne, P. Hans, A.E. Seret, A.A. Mouithys-Mickalad, M.D. Hoebeke, Quantification of lipid bilayer effective microviscosity and fluidity effect induced by propofol, Biophys. Chem. 114 (2005) $53-61$.

[44] M.Lj. Mihailovic, Z. Cekovic, in: S. Patai (Ed.), The Chemistry of the Hydroxyl Group, Part I, John Wiley and Sons, London, 1971. 